See discussions, stats, and author profiles for this publication at: https://www.researchgate.net/publication/262408165

\title{
Thermal design of multi-layered composite pipelines for deep water oil and gas production
}

Article in International Journal of Computer Applications in Technology · April 2012

DOI: 10.1504/IJCAT.2012.046311

CITATIONS

READS

0

164

3 authors, including:

8

Jian Su

Universidade Federal do Rio de Janeiro, Rio de Janeiro, Brazil

92 PUBLICATIONS 667 CITATIONS

SEE PROFILE

Some of the authors of this publication are also working on these related projects:

Doctoral Thesis View project

Capacitance sensor for void fraction measurement in two-phase flow View project 
\begin{tabular}{l} 
Thermal design of multi-layered composite pipelines \\
for deep water oil and gas production \\
\hline
\end{tabular}

\title{
Jian Su* and Djane R. Cerqueira
}

Nuclear Engineering Program, COPPE, Universidade Federal do Rio de Janeiro, Rio de Janeiro, Brazil

E-mail: sujian@lasme.coppe.ufrj.br

E-mail: deca_rj@hotmail.com

*Corresponding author

\section{Su-Zhen Wang}

College of Automation Engineering, Qingdao Technological University, Qingdao 266520, China

E-mail: wangsuzhen2020@163.com

\begin{abstract}
This paper addresses the technological challenges in the thermal design of multi-layer composite pipelines for offshore production of oil and gas in deep waters. An overview is provided for the flow assurance requirements, the thermal insulation systems and active heating of pipelines. A basic framework of thermal design is presented that consists of steady-state and transient heat-transfer analysis of multi-layered composite pipelines. Under some simplifying hypotheses, the thermal profile of the produced fluid along the pipeline is given by an analytical solution. Transient heat-transfer during a cold-down of a typical pipeline for deep water oil and gas production is simulated by numerical solution of conjugate heat-transfer in the solid and energy transport in the fluid.
\end{abstract}

Keywords: active heating; flow assurance; offshore systems; pipelines; thermal design; thermal insulation.

Reference to this paper should be made as follows: Su, J., Cerqueira, D.R. and Wang, S-Z. (2012) 'Thermal design of multi-layered composite pipelines for deep water oil and gas production', Int. J. Computer Applications in Technology, Vol. 43, No. 3, pp.248-259.

Biographical notes: Jian Su graduated in Engineering Thermophysics from the University of Science and Technology of China (USTC), received his MSc in Engineering Thermophysics at the Institute of Engineering Thermophysics, Chinese Academy of Sciences and his DSc in Mechanical Engineering at the Federal University of Rio de Janeiro (UFRJ). He is an Associate Professor at the Nuclear Engineering Program, Graduate School and Research in Engineering (COPPE), Federal University of Rio de Janeiro. His research interests include issues related to fundamentals of thermodynamics, fluid mechanics and heat-transfer, multi-phase systems, nuclear reactor thermal hydraulics, flow assurance of deep water oil and gas production and aerodynamic heating of re-entry satellites.

Djane R. Cerqueira graduated in Mechanical Engineering from the Federal University of Rio de Janeiro (UFRJ). She received her MSc in Nuclear Engineering at COPPE/UFRJ. She is a Senior Engineer working in petroleum and energy sectors.

Su-Zhen Wang graduated and received her MSc in Environmental Engineering from Ocean University of China, Qingdao. She received her DSc in Environmental Engineering at Ocean University of China. She is a Lecturer at Qingdao Technological University. Her research interests include process computer control, information management and decision-making.

\section{Introduction}

Flowlines and risers are essential in offshore systems for oil and gas production. Thermal design of flowlines/risers has received increasing attention due to possible gas hydrate formation and paraffin deposition at high pressure/ low temperature conditions associated with deep water production systems. In this paper, the main issues of thermal design of multi-layered composite pipelines will be addressed within the context of integrated design and management of offshore systems for oil and gas production. 
Thermal design is an integrating part of flow assurance, which addresses all issues important to maintain the flow of oil and gas from reservoir to reception facilities. Flow assurance requires a carefully considered plan to insure that sub-sea well production can be as nearly continuous as feasible during normal operation, with minimum hydrate formation and wax deposition and that production can be rapidly suspended when necessary and later resumed with minimum difficulty and downtime. Flow assurance encompasses primary design requirements such as line diameter and insulation requirements, as well as the prediction and control of potential solids. Flow assurance must address how the production system will operate during various modes (start-up, steady-state, shutdown, rate change and others) throughout the operating life; in doing that, operating strategies consistent with the system design should be developed. For oil and gas field developments in deep water and ultra deep water, flow assurance issues can have a significant impact on the final system design. Therefore, it is necessary to consider both the structural and flow assurance requirements simultaneously when designing the optimal production system. Once a specific flowline/riser type has been determined to be structurally feasible in ultra deep water, the flow assurance aspects may prove to be the bottleneck in the implementation of this configuration. Conversely, the flow assurance assessment may lead to system requirements that are structurally unachievable at these water depths. Both of these issues, along with the economic cost associated with each, need to be viewed together in order to arrive at the viable solution. The general issues of flow assurance in deep water oil and gas production have been discussed in several works (Minami et al., 1999, 2000; Golczynski and Niessen, 2001; Barney, 2002; Brown, 2002; Davalath, Hurtado and Keig, 2002; Pausche, Creek and Stair, 2002; Saint-Marcoux, 2002; Saint-Marcoux and Kennedy, 2002; Su, 2003).

The paper is organised as follows. First, the general issues of flow assurance requirements are addressed. Second, the state-of-the-art of thermal insulation systems will be reviewed. Thrid, the increasingly important activing heating of pipelines are discussed. Fourth, the methodology of steady-state thermal design will be presented. Fifth, the methodology of transient heat-transfer analysis will be presented. Simulation of cool-down of a typical sandwich pipeline is presented as a numerical example of application.

\section{Flow assurance requirements}

It is imperative that all relevant flow assurance issues be addressed as early as possible, preferably in the conceptual design phase, to properly define the optimal production system for a given development. More and more, the oil industry is conducting parametric studies of their developments, evaluating a wide range of possible operating conditions to properly evaluate the merits and pitfalls of both sub-sea tiebacks and dry tree completions before deciding on which system to implement. Golczynski and Niessen (2001) discussed the flow assurance issues for a hypothetical black oil field in 7,000 ft water depth for both a sub-sea tieback and dry tree riser option. At these water depths, the transient behaviour of the system (cold-down, depressurisation, etc.) becomes increasingly important and may often dictate the system design. Both the sub-sea tieback and dry tree riser designs must allow for a significant temperature drop under steady-state conditions due to vast elevation changes from the mudline to the surface. This temperature drop, where classically neglected in shallow water developments, can now constitute $50 \%$ (or more) of the overall system temperature drop. Furthermore, the dominance of the riser portion with regards to the thermal performance of the system enables sub-sea tiebacks from long-rang distances, upto potentially 50 miles, before the flowline impact even begins to approach the riser impact from a thermal and hydraulic perspective.

Steady-state analysis alone is not sufficient to properly define the flow assurance challenges for an ultra deep water development. Rather, the transient behaviour during cooldown and depressurisation must also be addressed. As small changes in fluid properties or reservoir properties can significantly impact the flow assurance results, it is recommended that studies encompassing a wide range of operating parameters be undertaken as early in the design phase as possible to provide the operator with the information they need to make an educated choice about how best to develop their ultra deep water field.

The key input into the flow assurance process is the proper acquisition and analyses of fluid samples provided by at least one exploratory well from each of the individual fields and improved by subsequent production. During the pre-project phase, fluids from exploration wells should be analysed to evaluate the flow assurance risks and set preliminary requirements for sub-sea production system design and operational strategies. This early assessment establishes the requirements for extensive thermal insulation of the sub-sea system not only to cover both hydrate formation and wax deposition risks but also for the injection of chemicals and methanol at the Xmas tree and well level. Evaluation of new information, made available during the project phase and development of operational procedures will generate design changes and improvements. Close cooperation between the field operation engineer, flow assurance engineer and system engineer will facilitate the implementation of operability aspects and late modifications to the system design (Saint-Pierre, Constant and $\mathrm{Vu}, 2002$ ).

A refined method to flow assurance was presented by Saint-Marcoux (2002), which consists of a systematic review of all operating conditions for the facilities under design, including warm-up, well start-up, steady-state design conditions (early, mid and late life), shut down (planned and unplanned) and blockage remediation. The functional analysis may be seen as a comprehensive review of all phases of the system whether operating at design conditions, during transient phases or during non-producing conditions. The steady-state is considered first, using available software for multi-phase flow analysis: e.g. PIPESIM, OLGA, PLAQ and TACITE, among others. 
The available pressure differential determines the minimum line size; the temperature differential determines the minimum flow rate, assuming that heavy slugging conditions are avoided, for example, with riser base gaslift. As no significant wax deposition will occur when the fluid is not circulating, the shutdown issue is dominated by hydrate formation avoidance, using methanol injection, displacement by dead oil, depressurisation in the case of passive insulation or using active heating to maintain the produced fluid temperature above the hydrate formation temperature. It is recognised that during cool-down the fastest temperature drop will occur on singular points such as: manifolds, valves with unprotected actuators, connectors, bulkheads and field joints. The prediction of heat loss during cool-down requires finite difference analysis for simple geometry and finite element analysis (e.g. ANSYS) for complex geometry. The detailed behaviour of the fluid during its cool-down may be modelled by using Computational Fluid Dynamics (CFD) package such as CFX or FLUENT. Start-up is performed in accordance with carefully planned procedures that include: methanol injection, injection of hydrate inhibitors or hot oil circulation. After methanol has been injected in the well bores, warm-up may be conducted in two phases: line warm-up by hot oil circulation and well start-up. Warm-up as well as cool-down can be simulated by using transient multi-phase flow analysis code such as OLGA.

\section{Thermal insulation systems}

Sub-sea oil and gas field developments often require thermal insulation of sub-sea installations and pipelines to avoid gas hydrate and wax formation. Gas hydrate and wax deposits may cause total blockage and especially gas hydrates may be difficult and extremely costly to remove. The problem occurs since both wax and hydrates can occur above seabed temperature. Typical wax appearance temperatures are $30-50^{\circ} \mathrm{C}$ while hydrate formation temperature is typically $20^{\circ} \mathrm{C}$ at 100 Bar. A typical curve of gas hydrate formation is shown in Figure 1, where gas hydrate forms to the left of the curve in the temperaturepressure diagram and no gas hydrate forms to the right of the curve. Alternatives to thermal insulation were chemical wax and gas hydrate inhibitors, which are available; however, the volumes required to prevent hydrate or wax without thermal insulation may sometimes be impracticable, though more often they accumulate a significant cost over the long run. Although these chemicals can be recovered to some degree, this incurs the additional expense of recycling equipment that occupies valuable space at the offshore processing facility. Depressurisation of the sub-sea production system is also used to avoid hydrate formation, but this requires large flaring capacity and might require very low design temperatures on production risers. For some, deep water fields depressurisation might not be feasible because, even after depressurisation, the pressure at seabed level would still be too high and cause hydrate formation at ambient temperatures.
Figure 1 Typical curve of gas hydrate formation in pressuretemperature diagram

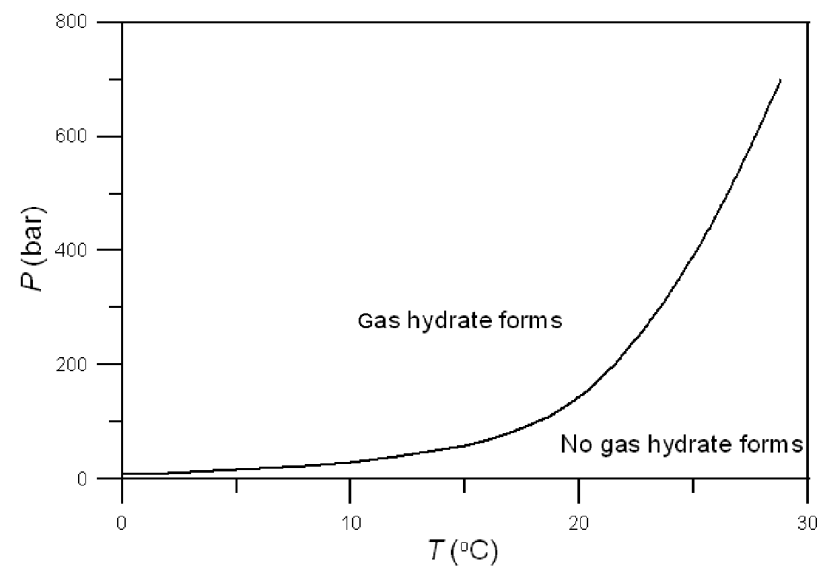

During steady-state production, thermal insulation and chemical inhibition are rather straightforward to plan for, while shutdown situations are more difficult. Although chemical inhibition may be used for a planned shutdown, there are still a number of unplanned shutdowns where sufficient thermal insulation can avoid too rapid cooling to hydrate formation temperature before compensating measures can be initiated. Typical for these situations is that emergency power is not available, thus requiring passive solutions. Sub-sea equipment contracts usually specify sufficient thermal insulation performance to stay above hydrate formation temperature for typically $8-12$ hours after a shut-in. For practical reasons, only the pipe sections of sub-sea equipment have traditionally been insulated with an external layer of polymer foam or solid coating. However, due to the complexity of sub-sea equipment, including valves, support beams, instrumentation and connections, there can be significant gaps in the insulation, giving cold spots or heat sinks that draw heat from the warmer sections of piping. To extend the cool-down time before hydrate and wax deposits form, it is required to eliminate potential cold spots making the thermal insulation of sub-sea equipment more complex and costly and, in some cases, not feasible.

The main materials used in the insulation industry consist of polymer materials such as polypropylene, polyurethane and epoxy. These insulation materials come in four main forms: solid, blown foam, syntactic and composite syntactic. Solid insulation materials mainly consist of the polymer material on its own in solid form without any reinforcements or modifications to its physical structure. Solid insulation materials are relatively dense compared with other insulation materials; solid polypropylene has a density of approximately $900 \mathrm{~kg} \mathrm{~m}^{-3}$ and is therefore almost neutrally buoyant. Blown foams are produced by introducing air bubbles into a material. This provides a material with a very low density (typically between 50 and $300 \mathrm{~kg} \mathrm{~m}^{-3}$ ). Blown foams are limited to water depths of approximately $600 \mathrm{~m}$ or Pipe-In-Pipe (PIP) applications. Syntactic and composite syntactic foams have been specifically developed for deep water applications. These materials offer the advantage of high strength and 
low density. Syntactic foams generally consist of small hollow spherical structures, called microspheres, incorporated into a solid polymer matrix. It is the microspheres that provide high hydrostatic strength to the polymer. Microspheres are typically between 50 and 200 microns in diameter and are commonly made from glass. Typical densities for syntactic foams are $600-800 \mathrm{~kg} \mathrm{~m}^{-3}$. Syntactic foam systems are designed to operate in water depths of upto $6000 \mathrm{~m}$. Composite syntactic foams are similar to syntactic foams, but also contain larger hollow spherical structures called macrospheres, which are over $1 \mathrm{~mm}$ in diameter and can be as large as $75 \mathrm{~mm}$ in diameter. The use of macrospheres helps to reduce the density of the material further from that of a syntactic foam and still provide reasonable hydrostatic strength. In general, microspheres provide higher strength than macrospheres. Macrospheres are generally made from reinforced thermoplastics. Typical densities for composite syntactic foams are $400-600 \mathrm{~kg} \mathrm{~m}^{-3}$. Composite syntactic foam systems have operational depths of upto $3000 \mathrm{~m}$. The most common polymer materials used for thermal insulation are polyurethane (thermoplastic and elastomeric), epoxies (amine or anhydride cured) and polypropylene. Other polymers used include PVC, polyester, rubbers and polystyrene. In addition to polymer foams, a wide range of PIP insulation materials have been used including fly-ash, foamed cement, mineral wool, gels (kerosene, monoethylene) and silica gels.

In recent years, prevention of hydrate formation in the sub-sea production equipment has become a major concern. During a production shutdown, hot produced fluids become stagnant and are cooled by the surrounding cold water, resulting in possible hydrate formation. Such blockage may plug the bore of a sub-sea tree, tree piping, jumper, manifold and flowlines, causing loss of production and inability to open or close valves. Janoff and Davalath (2002) presented an overview of the section and design process of insulation materials for deep water sub-sea completion and production equipment. The thermal insulation materials are required to have the following characteristics: low thermal conductivity, ability to retain its insulating properties under hydrostatic compression and long-term exposure to sea water, ability to fit into limited available space, ease of installation and repair, ability to withstand handling impacts and corrosion protection. Trees and manifolds represent a difficult application for insulation because of the complex and irregular surfaces. Different types of insulation materials used for sub-sea equipment include epoxy syntactic foams, flexible epoxies, urethanes and vulcanised elastomers. Janoff and Davalath (2002) presented several examples of FMC's successful field application of thermal insulation technology in water depth upto $5,000 \mathrm{ft}$ and discussed the advantages and disadvantages of the materials with regard to sub-sea components. Small-and large-scale testing of thermal insulation for sub-sea wellhead and production equipment is presented by Janoff et al. (2002). Thermal behaviour of complex geometric configurations in dry tree risers is also addressed by Golczynski and Brown (2002).

Jackson and Simonsen (2002) presented a conservative, robust design of sub-sea thermal insulation systems suitable for use in pipeline insulation design process and discussed the evaluation of thermal insulation materials. They pointed out that the properties of non-metallic materials are strongly influenced by how they are produced and processed into the final applied product. For example, spray-applied foams show considerable axial anisotropy in their compressive strength and thermal conductivity due to the dependency on the rise direction. Cast foams show also axial anisotropy, but as the rise direction is generally $90^{\circ}$ offset to the sprayapplied variant, the case is opposite. Injection-moulded syntactic materials show a strong dependence on the pumping and mixing dynamics during the moulding process. Cross-head extruded polypropylenes show also different mechanical and thermal performance to sideextruded products, as the development of the foamed structure takes place under different conditions. It is thus important that data used in the design and documentation phase for a Wet Insulated Single Pipe (WISP) system be measured on the material that has been applied to pipe using commercial equipment of the same type as used in the final production. Evaluation of the insulation materials for ultra deep sea flow assurance was also discussed by Choqueuse, Chomard and Bucherie (2002). van Belle (2002) presented advances in hightemperature syntactic foam technology for offshore systems.

There are currently a wide variety of insulation systems available for deep water sub-sea applications. These systems are applied in a number of different configurations including externally bonded systems, pre-manufactured insulation modules that are strapped on to sub-sea structures and PIP insulation systems. The limits associated with current insulation systems include lack of experience on the performance of these systems in longterm deep water service and relatively low temperature limits when exposed to hot/wet conditions. At present, tests for assessing their thermal and physical properties are manufacturer-dependent and, for a purchaser of such systems, need to be interpreted across a range of existing and new materials and manufacturer specifications. The immediate and long-term effects of temperature, hydrostatic pressure and environmental exposure are not yet fully understood. Currently, there is a lack of agreedupon standards for insulation materials. There is a requirement in the industry for the development of consistent standards for the specification, design, materials, manufacturing and testing of insulation materials and systems.

The state-of-the-art for thermal insulation systems for deep water applications was recently reviewed by Grealish and Roddy (2002). The capabilities of alternative systems are reviewed and evaluated. The key issues associated with each system type and critical parameters for the most common insulation materials are presented and discussed. The main types of insulation systems can be classified as 
integral external insulation, multi-layer insulation, insulation modules, PIP insulation and bundle insulation.

Integral external insulation comprises insulation that is directly bonded to the insulated surface. The types of materials used are solid, syntactic and composite syntactic. This type of insulation may be applied by either casting, spraying or extruding. Alternatively, the insulation material can be injected into a sleeve that is centred around the product to be insulated. Once applied, the material may take a certain amount of time to set. Some materials may take upto 36 hours to set while other materials can take as little as $10 \mathrm{~min}$. For applications such as steel catenary risers, which experience a significant amount of dynamics during their lifetime, the integral external insulation needs to be flexible and strong enough to accommodate the associated motions and stresses, respectively. Other scenarios in which flexibility is required is installation through reeling. In this case, the insulation material must be flexible enough to be stored on a reel and not to exceed its strain at break. Several insulation manufacturers have specific products that offer the required flexibility to cater for these applications. External integral insulation is particularly suitable for subsea wellhead equipment that usually have complex surface geometry. This is because the material can be easily applied to give a coating of uniform thickness to such geometry. Flexibility of the insulation material is especially important for these applications, since they may experience some movement in service. To protect metal surfaces from corrosion effects, external integral insulation usually incorporates a corrosion protection layer that is commonly made from Fusion Bonded Epoxy (FBE). This layer is applied directly to the metal surface before the insulation layer. Alternatively, the insulation could provide the corrosion protection requirements itself and this is an option being promoted by some suppliers. A drawback with external integral insulation is that it is permanent; once applied, it cannot be removed easily. The materials used in these systems have relatively good thermal conductivity with a typical value being $0.15 \mathrm{~W} \mathrm{mK}^{-1}$, although other systems with better thermal conductivity are available.

Multi-layer insulation systems are a sub-category of integral external insulation systems and consist of a number of different layers that make up the insulation. A typical configuration could include a solid layer, a blown foam layer and a syntactic foam layer. Each layer performs a specific function. The solid layer is normally placed directly over a corrosion protection layer and provides temperature resistance. The syntactic layer provides hydrostatic strength and good insulation properties. The blown foam layer is usually the outermost layer and provides the best insulation properties. Because there is a thermal gradient across the pipe, the blown foam layer is subjected to a significantly lower temperature than the inner layers. This is advantageous because blown foams do not have the temperature resistance of the material in the solid state. Other layers that are often included in multi-layer systems include adhesive layers, which help to bond layers together and shield layers, which protect the outermost layer from damage. The various layers can be applied using an extrusion process. The benefit of multi-layer systems is that the thickness and density of each layer can be tailored to suit the particular application. For example, resistance to hydrostatic pressure and temperature can be achieved by adjusting the density of the various layers. Insulation modules consist of pre-fabricated sections of insulation, which are attached to the insulated structure without being directly bonded to it. The types of materials generally used for this type of system are syntactic and composite syntactic foams. The benefit of insulation modules for riser tower applications, for example, is that the geometry can be customised to accommodate not only the main riser but any auxiliary lines. It can also be removed during the service life. The insulation is typically attached by virtue of straps or bolts. For flowline and riser applications, the insulation can come in the form of cylindrical half-shells that are attached together to enclose the structure. For riser tower applications, the insulation is usually attached by building up several moulded sections of material around the structure. One disadvantage with insulation modules is that there are inevitable gaps present either between half shells or moulded sections. The consequence of this is that convection currents can arise in the gaps and hence reduce the insulating capability.

Pipe-In-Pipe (PIP) systems have been lately proposed as viable solutions to such problems (Nutall and Rogers, 1998; Franklin and Wright, 1999; Trout and Sahota, 1999). They consist of two concentric metal pipes in which the annulus is either filled with a nonstructural insulating material or is used to carry water for well injection, umbilical cables, etc. Usually, internal and external pipes are designed independently against failure under internal and external pressures, respectively, combined with installation loads, mainly longitudinal bending. The factors governing the collapse and propagation of buckles in single pipes and PIP systems under external pressure have been extensively studied in the past, so that nowadays deep water pipes can be safely designed (Murphey and Langner, 1985; Yeh and Kyriakides, 1998; Pasqualino and Estefen, 2001; Kyriakides, 2002; Kyriakides and Vogler, 2002). The benefit of PIP insulation is the ability to use the materials with the highest insulation properties, which would normally be unsuitable for use if not protected by the outer pipe. Typical PIP insulation materials include polyurethane or polypropylene blown foam, gases, such as nitrogen and air and microporous silica. Low-density polyurethane foam has a low thermal conductivity value of approximately $0.025 \mathrm{~W} \mathrm{mK}{ }^{-1}$, which is close to that of air. Microporous silica consists of an open cellular structure reinforced with ceramic fibres. It gives the lowest possible thermal conductivity currently available, of approximately $0.02 \mathrm{~W}$ $\mathrm{mK}^{-1}$, which is less than that of air. The disadvantage of microporous silica is that it is a very expensive material. PIP insulation is usually applied by pumping the material into the annulus and allowing it to cure. Alternatively, insulation modules similar to those discussed previously can also be positioned inside the annulus. Because a steel carrier pipe is 
used, the PIP system has almost unlimited water depth capability though for ultra deep waters there may not be the capability to install the PIP system with current installation techniques. The other advantage of PIP insulation is that the insulation material is protected from the effects of water ingress, provided the annulus is not flooded. The main disadvantage of PIP insulation systems is the installation and fabrication costs compared with single bore pipes.

Bundle insulation systems are similar to PIP insulation systems, except that the bundle will house a number of pipes rather than just one. Bundle insulation systems impose more geometrical constraints on the insulation system, similar to insulation modules, in that the insulation must fit around multiple pipes.

Other systems that have been used for insulation or are under development include the following: vacuum systems (mainly used downhole); burial/trenching (potential in combination with a coating); electrical heating and hot water systems, which are to be discussed in Section 4.

\section{Active heating}

With increasing water depth and tieback distance, pipeline insulation becomes mandatory in all deep water developments. Active heating is required when passive thermal insulation alone is not sufficient to prevent wax deposition and hydrate formation. During extended production shutdown, gas hydrates can form and block the flowline unless necessarily time-consuming and/or complex prevention measures include hydrate injection and dead oil displacement of produced fluids. In an emergency shutdown, the flowline is only protected by the cool-down time of the insulation, since the prevention measures are not usually possible in the emergency shutdown situation. For production start-up or restart, hydrate inhibitor injection and/or other procedures such as hot oil circulation are necessary. Heated flowline/riser systems can significantly reduce the complexity of shutdown and start-up operations and provide better overall flow assurance.

Two methods of active heating of deep water pipelines have been studied in recent years: electrical heating and heating by a circulating heat medium.

Norwegian oil companies, cable manufacturers and pipeline installation companies conducted studies on electrical heating of multi-phase sub-sea pipelines and risers to prevent hydrate formation and wax plugs (Lervik, Kulbotten and Klevjer, 1997; Lervik et al., 1998; Halvorsen, Lervik and Klevjer, 2000). The evaluation of technical feasibility and cost estimates were carried out for a $50 \mathrm{~Hz}$ direct resistive heating system and for a system based on electromagnetic induction. The electrical rating of the systems depends on the heat requirement, pipe material and the pipeline. The feasibility of the concepts was verified through full-scale sub-sea tests. Results from the measurements were used to determine the characteristic parameters of the two systems on fields in the North sea. Halvorsen, Lervik and Klevjer (2000) reported that for a $400 \mathrm{~Hz}$ system cable the diameter will be approximately
$30 \mathrm{~mm}$ with conductor cross-section of $120 \mathrm{~mm}^{2}$. A $50 \mathrm{~Hz}$ system will typically require a cable diameter of approximately $50 \mathrm{~mm}$ and a conductor cross-section of $630 \mathrm{~mm}^{2}$. The voltage drop is typically $1 \mathrm{kV} \mathrm{km}^{-1}$ for heating a riser.

British Petroleum (BP) planned to develop the King project in Mississipi Canyon Block 85 (MC85) via a dual well, sub-sea production scheme (Harrison and Herring, 2000). The active heating system employs hot water circulating in the closed loop PIP annulus. External insulation around the jacket pipe and burial/backfill provide thermal insulation of the flowlines. Heat is extracted from the exhaust waste heat of three, $3.9 \mathrm{MW}$, electrical generator turbine drivers. A detailed model using the software tool, OLGA, was developed to investigate the feasibility of circulating heated fluid in an insulated PIP annulus to provide heat to King production. Results indicated that the circulation of $3180 \mathrm{~mm}^{3}$ (20,000 BPD) of heated water departing Marlin TLP at $66^{\circ} \mathrm{C}$ resulted in acceptable temperature profiles for the key King production scenario. By periodically reversing the Heated Water Circulation (HWC) path, the former 'cold' flowline would become the 'hot' flowline and the accumulated wax would be removed by remelting into the production steam. The HWC flow path has been equipped with switching valves to implement this feature in King development. It is found that the $895 \mathrm{~kW}(1,200 \mathrm{HP})$ pumping power was adequate to circulate the $3180 \mathrm{~mm}^{3}$ of heated fluid.

Chin, Prescott and Perera (2000) presented a computer model based on OLGA for analysing steady and transient multi-phase flow and heat-transfer in a three-flowline bundle with active heating. The bundle system analysed is a pipeline bundle system installed in the Gulf of Mexico. Three flowlines are surrounded by insulation and encased in a carrier pipe. During normal operation, the product fluid can flow in either one or two of the three flowlines. The third is the service line. When the pipeline is operated with active heating, hot oil is injected at platform. The injected oil is circulated through two of the three flowlines, while the product flows in the third line. The pigging loop is used as the turnover circuit for the heating fluid. The model simulates the thermal interaction among the multi-phase flowline, heating line and insulation layer. The heat-transfer between the outer surface of insulation, the pressurised nitrogen annulus and the carrier pipe is simplified by a modified conduction model. The steady-state performance of each line and the transient thermal response behaviour of the pipeline after a system shutin are determined.

$\mathrm{Su}$, Regis and Botto (2002) presented thermal analysis of combined thermal insulation and active heating. A global heat balance analysis of typical deep water pipelines for oil and gas production was first presented and it was shown that active heating is necessary for long pipelines due to technical limitations of passive thermal insulation systems. Two methods of combined active heating and passive insulation are then considered. By the first method, active heating is provided by circulating hot water in annulus. Under certain simplifying hypotheses, Su, Regis and Botto 
(2002) provide a close-form analytical solution for the temperature profiles of the produced fluid and heat medium. By the second method, active heating is provided by electrical resistance on the inner steel pipe. For this case, a heating method was proposed that minimises the power requirement for a given minimum temperature of produced fluid. Numerical results are shown for the second heating method. Significant reduction in power requirement might be achieved.

Felix-Henry and Secher (2002) presented a flexible pipe structure termed Integrated Production Bundle (IPB), which is a flexible riser assembly based on Integrated Service Umbilical (ISU) technology and other patented technologies, incorporating active heating, gas lift hoses and passive insulation. The advantages of the IPB are numerous:

1 Gathering several lines (produces, gas lift, umbilicals) in a single multi-bore pipe considerably simplifies the crowdness of the riser system and the sub-sea equipment. It also simplifies the offshore installation operations.

2 The integration of gas lift tubes improves the thermal performances of the bundle because the injected gas is 'hottest' at the coldest location, i.e. the top section.

3 The passive insulation keeps the arrival temperature above a critical value in standard service conditions.

4 The active heating can be switched on during shutdowns and start-ups or during critical production conditions (low production profile, low flowing temperatures and/or pressures).

Both heat-tracing technologies are qualified for IPBs: electrical and hot water circulation. There is no immediate preferred solution as both have their advantages. Electrical heat traces give an even distribution of energy along the IPB while the hot water brings more heat at the top end where it is most needed. The main advantage of electrical heattracing over hot water circulation is that it is much more compact regarding the design of the IPB. A system equipped with the heat tracers in the armour layers will have the same OD as a conventional insulated flexible pipe. This technology also enables the use of standard flexible pipe insulation. The limitations of the heat-tracing armours concept will be on the maximum heat power available and/or the maximum length achievable because of the small cross-section of conductors.

Laouir and Denniel (2001) reported a development programme launched in 2000 by Coflexip to introduce active heating for PIP systems. The active heated PIP is based on proven heat-tracing technology combined with standard reelable PIP design. Heating is generated by resistive cables using low voltage, which complements the PIP insulating performance. The cool-down simulation have shown that a temperature difference of a $30-35^{\circ} \mathrm{C}$ between the hydrocarbon product and the environment could be maintained with a typical heat input of $20-40 \mathrm{~W} \mathrm{~m}^{-1}$ for a well insulated heated PIP. Lower power inputs are sufficient to extend the cool down time of the PIP.
Similarly, Su, Cerquiera and Estefen (2003) proposed a concept of combine thermal insulation and active heating by inserting strips of electrical resistance into the sandwich pipes. They carried out a global heat balance analysis to determine the energy input requirement and then steadystate thermal analysis to determine the temperature distribution in a cross-section of the sandwich pipes under typical production conditions in ultra deep water. A mathematical model was developed for the analysis of steady-state heat-transfer in the sandwich pipes. The partial differential equations are solved by using a finite-volumebased numerical method. It is shown from the numerical results that with a power supply of $0.3 \mathrm{~V} \mathrm{~m}^{-1}$ and four copper strip with $1 \mathrm{~mm}$ thickness and $4 \mathrm{~mm}$ width, acceptable distributions of fluid temperature and pipe inner surface temperature are obtained. Lower power supply will increase the cross-section area of the heater; thinner heater strip will decrease the temperature difference between the produced fluid and the pipe inner surface, but may introduce difficulties in fabrication and installation. It can be seen that the sandwich pipe with active heating is a viable solution to meet severe flow assurance requirements of ultra deep water oil production.

Recently, Zhang et al. (2002) presented the thermal analysis and design of hot-water-heated production flowline bundles. Two design options are analysed and compared. One is a small hot water pipe attached to the production flow line (indirect heating) and the other is a large hot water pipe encasing the production flowline (direct heating). The direct heating design has the advantage of potentially more efficient heating due to the large heating area and the low thermal resistance between the hot water and the heated fluids. The system pressure drop is also expected to be lower than indirect heating due to the larger flow area for water. A major drawback is the higher cost of the bundle. With direct heating, the hot water pipe must be larger than the flowline pipe. Compared with indirect heating, which uses a much smaller hot water pipe than the production pipe, direct heating bundle requires more steel and thicker insulation to reach the same OHTC. Both factors increase the bundle cost. Because of the size and weight, the carrier pipe is also larger, heavier and more costly. The advantages of the indirect heating design are primarily the lower bundle cost because of the lower volume of steel for the hot water pipe, the smaller volume of insulation materials and smaller carrier pipe compared with direct heating. However, the thermal resistance between the heating water and the heated fluids is much larger than that for the direct heating design. This would result in longer warm-up time. The smaller pipe, while making heat loss to the environment lower than direct heating, tends to require high pump discharge pressure for the heating water. In addition, the installation method for indirect heating bundle is currently limited to towing. Direct heating bundles, on the other hand, can also be laid with the appropriate design for some developments. Zhang et al. (2002) concluded that both heating options can meet the design heating requirements, while each has its advantages and disadvantages. 
An analysis of transient heat-transfer in sandwich pipelines with active electrical heating was presented recently by $\mathrm{Su}$, Cerqueria and Estefen (2005). Three configurations of sandwich pipelines with solid polypropelene as thermal insulation material were studied by numerical simulation. Numerical results indicated that although the passive thermal insulation was adequate for steady-state production conditions, the active heating was required during either planned or unplanned cool-down. By comparing three cases studies, it was observed that the electrical heating power requirement per unit length was smaller if the thermal insulation layer was thicker. It was indicated that a compromise should be achieved in the pipeline specifications by considering both the higher capital expenses associated with thicker thermal insulation and the higher operational expense associated with higher power requirement.

\section{Steady-state heat-transfer}

Thermal design is a component of integrated design of offshore production systems, together with fluid system design and structural design. As design input data, the composition of the produced fluid is given so that the thermodynamic and transport properties can be calculated for given conditions of pressure and temperature. Generally, for an available pressure drop between the wellhead and the separator, an internal diameter of the flowline is chosen to start the design cycle by calculating the pressure drop at desired mass flowrate. The thicknesses of the pipelines are chosen by structural design criteria against internal and external limiting pressures. Thermal design starts by specifying the thermal insulation material and thickness. The temperature distribution along the pipeline, usually called thermal profile, can be calculated by steady-state heat-transfer analysis. The thermal profile will be used to refine the pressure drop calculation by improving the accuracy of fluid properties as a function of local temperature and pressure. An iterative design process will carried out until the output meets the fluid dynamic, heattransfer and structural integrity requirements.

Let us consider a multi-layered composite pipeline for deep water oil and gas production. Normally, the desired thermal profile of the produced fluid and the overall heat-transfer coefficient are used to specify an adequate pipeline configuration. The thermodynamic and tranport properties of the produced fluid are specified through the density, $\rho_{\mathrm{f}}$, the thermal conductivity $k_{\mathrm{f}}$, the specific heat $c_{\mathrm{p}, \mathrm{f}}$ and the viscosity $\mu_{\mathrm{f}}$. The geometrical configuration and material properties of the multi-layered composite pipeline are specified. The composite pipeline consists of $N$ concentrically cylindrical layers as shown in Figure 2.
Figure 2 Cross-section of a multi-layered composite pipeline

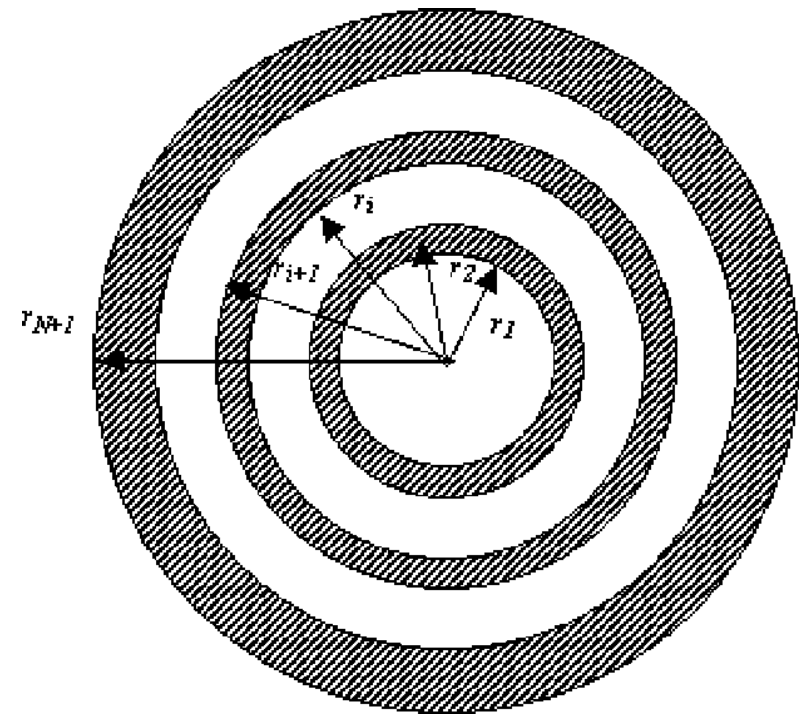

Each layer is assumed to be homogeneous, isotropic and with constant thermophysical properties. The adjacent layers are assumed to be in perfect thermal contact. The overall heat-transfer coefficient for a multi-layered composite pipeline is defined as

$$
U=\frac{1}{\frac{1}{h_{1}}+\sum_{i=1}^{N} \frac{r_{1}}{k_{1}} \ln \frac{r_{i+1}}{r_{i}}+\frac{r_{1}}{r_{N+1} h_{a}}}
$$

where $r_{i}$ and $r_{i+1}$ are the inner and outer radii of the $i$ th layer, respectively, $k_{i}$ is the thermal conductivity of the $i$ th layer, $h_{1}$ is the heat-transfer coefficient between the inner most layer and the produced fluid flowing inside and $h_{a}$ is the heat-transfer coefficient between the outermost layer and the environmental fluid.

The one-dimensional (1D) energy transport equation of the produced fluid is written as

$$
M_{\mathrm{f}} c_{\mathrm{p}, \mathrm{f}} \frac{\mathrm{d} T_{\mathrm{f}}(z)}{\mathrm{d} z}=-U 2 \pi r_{1}\left(T_{\mathrm{f}}-T_{\mathrm{m}}\right)
$$

subject to the initial conditon at the wellhead where the temperature of the produced fluid is specified.

$$
T_{\mathrm{f}}(0)=T_{\mathrm{f}, \mathrm{wh}}
$$

where ${ }^{\prime} M_{\mathrm{f}}$ is the mass flow rate of the produced fluid, $r_{1}$ is the inner radius of the innermost steel pipe, $L$ is the length of the pipeline. If $M_{\mathrm{f}}, c_{\mathrm{p}, \mathrm{f}}, U$ and $T_{\mathrm{m}}$ are constant, an analytical solution can be readily found for the thermal profile

$$
\frac{T_{\mathrm{f}}(z)-T_{\mathrm{m}}}{T_{\mathrm{f}, \mathrm{wh}}-T_{\mathrm{m}}}=\exp \left(\frac{-z U 2 \pi r_{1}}{M_{\mathrm{f}} c_{\mathrm{p}, \mathrm{f}}}\right)
$$


The steady-state temperature distribution in the composite medium can be determined to provide initial conditions for transient heat-transfer analysis of the cool-down of the pipeline, if the axial and circumferential heat conduction in the solid are neglected. As in steady heat conduction, the linear heat-transfer rate $Q$ is a constant in any closed circle in the pipeline and the heat flux in any radial co-ordinate can be easily determined.

$$
q_{i}=\frac{Q}{2 \pi r_{i}}
$$

The linear heat-transfer rate in the pipeline is given by

$$
Q=U 2 \pi r_{1}\left(T_{\mathrm{f}}-T_{\mathrm{m}}\right)
$$

The linear heat-transfer rate is used to determine the temperature difference across each layer

$$
T_{i+1}-T_{i}=\frac{Q}{2 \pi k_{i} \ln \frac{r_{i}+1}{r_{i}}}
$$

and then the temperature distribution in each layer

$$
\frac{T(r)-T_{i}}{T_{i+1}-T_{i}}=\frac{\ln \frac{r}{r_{i}}}{\ln \frac{r_{i+1}}{r_{i}}}
$$

\section{Transient heat transfer}

We consider a composite medium consisting of $N$ concentrically cylindrical layers, as shown in Figure 2. Each layer is considered to be homogeneous, isotropic and with constant thermal properties. The adjacent layers are assumed to be in perfect thermal contact. There is no heat generation in the medium. The mathematical formulation of the $1 \mathrm{D}$ heat conduction problem is written as

$$
\frac{\partial T_{i}}{\partial t}=\frac{\alpha_{i}}{r} \frac{\partial}{\partial r}\left(r \frac{\partial T_{i}}{\partial r}\right), \quad r_{i}<r<r_{i+1} \quad i=1, \ldots, N
$$

where $T_{i}$ is the temperature in the $i$ th layer, $\alpha_{i}=k_{i} / \rho_{i} c_{p i}$ its thermal diffusivity, $k_{i}$ the thermal conductivity, $\rho_{i}$ the density and $c_{p i}$ the specific heat. The inner and outer radii of the $i$ th layer are $r_{i}$ and $r_{i+1}$, respectively.

Equation (9) is to be solved with the following boundary and interface conditions:

$$
\begin{aligned}
& h_{1}\left(T_{\mathrm{f}}-T_{1}\right)=-k_{i} \frac{\partial T_{1}}{\partial r}, \quad \text { at } r=r_{1} \\
& h_{a}\left(T_{\mathrm{m}}-T_{\mathrm{N}}\right)=-k_{n} \frac{\partial T_{N}}{\partial r}, \quad \text { at } \quad r=r_{N+1} \\
& T_{i}=T_{i+1}, \quad \text { at } \quad r=r_{i+1} \quad i=1, \ldots, N \\
& k_{i} \frac{\partial T_{i}}{\partial r}=k_{i+1} \frac{\partial T_{i+1}}{\partial r}, \quad \text { at } \quad r=r_{i+1} \quad i=1, \ldots, N
\end{aligned}
$$

where $T_{\mathrm{f}}$ is the temperature of the fluid transported in the pipeline, $h_{1}$ is the heat-transfer coefficient between the innermost layer and the fluid inside it, $T_{\mathrm{m}}$ is the temperature of environmental fluid, $h_{\mathrm{a}}$ is the heat-transfer coefficient of between the outermost surface and environmental fluid.

The initial conditions for temperatures in each layer are

$$
T_{i}(r, 0)=T_{i 0}(r), \quad r_{i} \leq r \leq r_{i}+1 . \quad i=1, \ldots, N
$$

The mathematical model constituted by Equations (9) to (14) has been solved by a variety of methods. In this work, we solved the system of partial differential equations consisting of Equations (9) to (14) using the second-order accurate Crank-Nicolson finite difference method (Anderson, Tannehill and Pletcher, 1984).

Neglecting the effects of flow transient, we consider a steady fully developed flow with an average velocity $u$ of a produced fluid with constant properties transported in a pipeline of circular transversal section as shown in Figure 3. The 1D transient energy equation for the produced fluid is written as

$$
\frac{\partial T_{\mathrm{f}}}{\partial t}+u \frac{\partial T_{\mathrm{f}}}{\partial z}=-\frac{2 q_{r_{1}}}{r_{1} \rho_{\mathrm{f}} c_{\mathrm{p}, \mathrm{f}}}
$$

and heat flux in the inner surface of the pipeline is given by

$$
q_{r_{1}}=h_{1}\left(T_{f}-T_{r_{1}}\right)
$$

where $\rho_{\mathrm{f}}$ is density of the produced fluid, $c_{\mathrm{p}, \mathrm{f}}$ its specific heat, $r_{1}$ is the inner radius of the pipeline, $T_{r_{1}}$ is the wall temperature and $h_{1}$ is the heat-transfer coefficient between the flow and the pipeline.

Figure 3 Longitudinal view of a pipeline

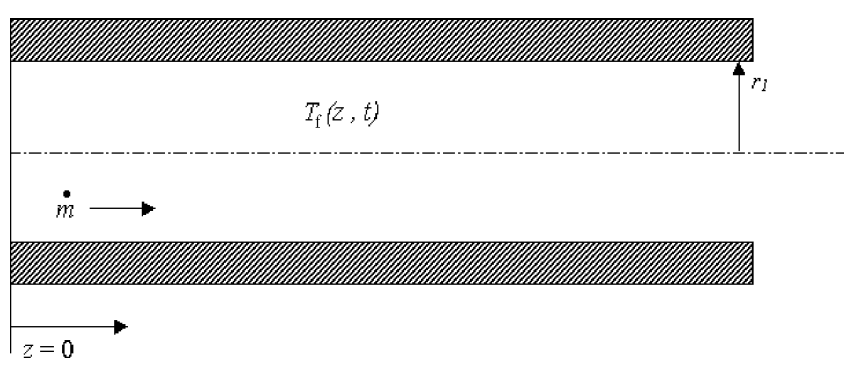

Equation (15) is to be solved with an initial temperature distribution of the fluid along the pipeline of length $L$ and an inlet boundary condition in the wellhead

$$
\begin{aligned}
& T_{\mathrm{f}}(z, 0)=T_{\mathrm{f} 0}(z) \text { at } t=0 \\
& T_{\mathrm{f}}(0, t)=T_{\text {fin }}
\end{aligned}
$$

The mathematical model formed by Equations (15) to (18) is now solved by a second-order accurate explicit finite difference scheme initially developed by Warming and Beam (1975): 
Predictor

$$
T_{\mathrm{f}_{j}}^{\overline{n+1}}=T_{\mathrm{f}_{j}}^{n}-\lambda u\left(T_{\mathrm{f}_{j}}^{n}-T_{\mathrm{f}_{j-1}}^{n}\right)-\frac{\Delta t 2 h_{1}\left(T_{\mathrm{f}_{j}}^{n}-T_{r_{1}}\right)}{r_{1} \rho_{\mathrm{f}} c_{\mathrm{p}, \mathrm{f}}}
$$

Corrector

$$
\begin{aligned}
T_{\mathrm{f}_{j}}^{\overline{n+1}}= & \frac{1}{2}\left[T_{\mathrm{f}_{j}}^{n}+T_{\mathrm{f}_{j}}^{\overline{n+1}}-\lambda u\left(T_{\mathrm{f}_{j}}^{\overline{n+1}}-T_{\mathrm{f}_{j-1}}^{\overline{n+1}}\right)\right. \\
& \left.-\lambda u\left(T_{\mathrm{f}_{j+1}^{n}}^{n}-2 T_{\mathrm{f}_{j}}^{n}+T_{\mathrm{f}_{j-1}}^{n}\right)-\frac{\Delta t 2 h_{1}\left(T_{\mathrm{f}_{j}}^{\overline{n+1}}-T_{r_{1}}\right)}{r_{1} \rho_{\mathrm{f}} c_{\mathrm{p}, \mathrm{f}}}\right]
\end{aligned}
$$

where

$$
\lambda=\frac{\Delta t}{\Delta x}
$$

and the subscript $j$ corresponds to the nodes in $z$ variable and the subscript $n$ corresponds to the $t$ variable, while the superscript $\overline{n+1}$ corresponds to an intermediate evaluation in the time variable.

\section{Applications}

Numerical solution of the mathematical models was implemented in a computer program in Fortran90. All features described in the previous sections are included in the computational implementation. For the shutdown calculation, the steady-state heat transfer analysis is implemented in sub-routines to generate initial temperature of produced fluid and initial temperature of the multilayered composite pipe. At each time step, the transient heat conduction equation in the solid and the energy equation of produced fluid are solved. In this way, we can follow the transient history of temperature in both produced fluid and the composite pipe. The fluid temperature history can be used to determine the necessary quantity of chemical inhibitors to avoid wax deposit or hydrate formation.

As a numerical example of thermal design, we simulated an hypothetical pipeline with a length of $80 \mathrm{~km}$ and an inner diameter of 6 inch $(0.1524 \mathrm{~m})$, in lack of more realistic pipeline and production well data. The composite pipeline in PIP configuration consists of two concentric steel pipes with same thickness and properties with the annulus filled with polypropelene foam. The thermophysical properties and the thickness of the layers are given in Table 1. The overall heat-transfer coefficient of the pipeline is 1.007 $\mathrm{W} \mathrm{m}{ }^{-2}{ }^{\circ} \mathrm{C}$.

Table 1 Properties of the layers of the composite pipeline

\begin{tabular}{lcccc}
\hline Material & $\rho\left(\mathrm{kg} \mathrm{m}^{-3}\right)$ & $\begin{array}{c}c_{p} \\
\left(\mathrm{~J} \mathrm{~kg}^{-1}{ }^{\circ} \mathrm{C}\right)\end{array}$ & $K\left(\mathrm{~W} \mathrm{~m}^{-1}{ }^{\circ} \mathrm{C}\right)$ & $\begin{array}{c}\text { Thickness } \\
(\mathrm{mm})\end{array}$ \\
\hline Stainless steel & 7850.0 & 486.0 & 54.0 & 3.175 \\
Polypropylene & 310.0 & $2,000.0$ & 0.025 & 76.2 \\
foam & & & & \\
\hline
\end{tabular}

The wellhead temperature of the produced fluid is taken as $76.0^{\circ} \mathrm{C}$ and the sea water is $4.0^{\circ} \mathrm{C}$. A mass flow rate of
$19.5 \mathrm{~kg} \mathrm{sec}^{-1}$ is assumed with a constant density of $875 \mathrm{~kg}$ $\mathrm{m}^{-3}$ and a specific heat of $2700 \mathrm{~J} \mathrm{~kg}^{-1}{ }^{\circ} \mathrm{C}$.

The numerical results of transient history of fluid temperature in a simulated shutdown is shown in Figure 4. We see that after 10 hours the minimum temperature of the produced fluid drops to $29.8^{\circ} \mathrm{C}$, above roughly at the hydrate formation temperature for deep water application. Ten hours is an adequate time interval to provide the necessary chemical inhibitors. The key factor in this project is the low thermal conductivity of the polypropelene foam used as the thermal insulator in the annulus. Comparing with the numerical example presented by $\mathrm{Su}$ and Cerqueira (2001), where solid polypropelene was used as thermal insulator, we can see the rapid technological advance in the past 4 years. In that case, with 3 inch solid polypropelene insulation in a $27 \mathrm{~km}$ pipeline, the minimum temperature of the produced fluid drops to $26.5^{\circ} \mathrm{C}$ after 4 hours. The example is used to show the potential of proposed mathematical model and solution techniques. For real-life application, more accurate thermodynamic properties and an adequate multi-phase flow model are needed to obtain quantitatively correct results.

Figure 4 Typical temperature distributions of produced fluid along the pipeline during cool-down

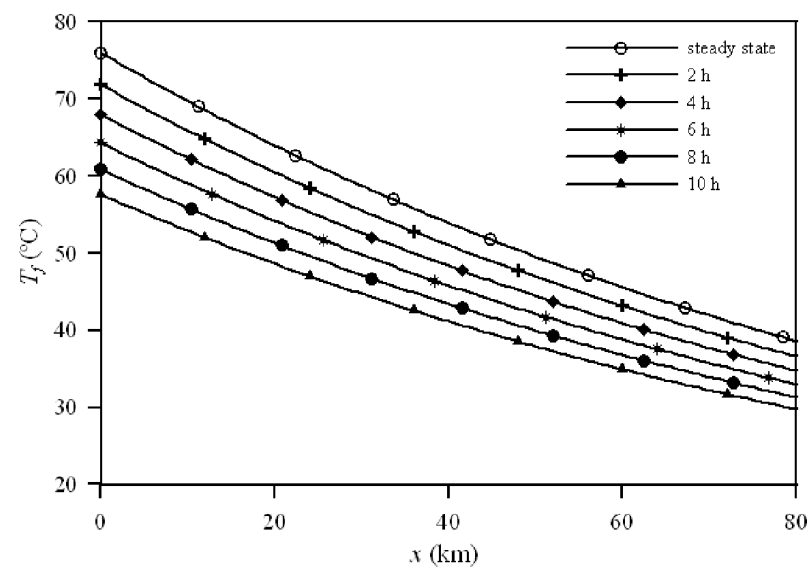

\section{Concluding remarks}

The thermal design of multi-layered composite pipelines for deep water oil and gas production is discussed within the context of integrated design of offshore systems. As shown in the preceeding discussions, the design of an adequate pipeline system envolves structural, thermal, fluiddynamic, material, manufacturing, installation and operation considerations. All aspects should be addressed in an integrated way in the early stage of field development. After an overview of the state-of-art of thermal insulation systems and active heating technology, a basic framework of thermal design was presented, followed by a numerical example in which polypropelene foam was used as thermal insulation material in a $80 \mathrm{~km}$ long pipeline. Finally, it should be emphasised that accurate evalution of fluid and material properties are crucial for a successful thermal design of the composite pipeline system. 


\section{Acknowledgements}

The authors acknowledges CNPq, CAPES and FAPERJ of Brazil for supporting this work. They are grateful to Prof R.Y. Qassim, the Editor of the Special Issue on Offshore Systems, for the kind invitation and encouragement.

\section{References}

Anderson, D.A., Tannehill, J.C. and Pletcher, R.H. (1984) Computational Fluid Mechanics and Heat Transfer. Washington, DC: Hemisphere Publishing.

Barney, G. (2002) 'Girassol: the sub-sea production system presentation and challenges', Paper OTC-14170 presented at the 2002 Offshore Technology Conference, Houston, Texas. In proceedings.

Brown, L.D. (2002) 'Flow assurance: a $\pi^{3}$ discipline', Paper OTC14010 presented at the 2002 Offshore Technology Conference, Houston, Texas. In proceedings.

Chin, Y.D., Prescott, C.N. and Perera, R. (2000) 'Multi-phase flow and thermal analysis of an insulated multiple flowline bundle', Paper presented at the ETCE/OMAE2000 Joint Conference, New Orleans. In proceedings.

Choqueuse, D., Chomard, A. and Bucherie, C. (2002) 'Insulation materials for ultra deep sea flow assurance: evaluation of the material properties', Paper OTC-14115 presented at the 2002 Offshore Technology Conference, Houston, Texas. In proceedings.

Davalath, J., Hurtado, M. and Keig, R. (2002) 'Flow assurance management for Bijupira and Salema field development', Paper OTC-14052 presented at the 2002 Offshore Technology Conference, Houston, Texas. In proceedings.

Felix-Henry, A. and Secher, P. (2002) 'Flexible risers with active heating: recent developments with electrical heating', Paper presented at the 3rd Workshop on Sub-sea Pipelines, Rio de Janeiro. In proceedings.

Franklin, J.F. and Wright, A. (1999) 'The development of thermal insulation systems for deep water pipelines', Paper presented at the 13th International Conference on Pipeline Protection, pp.217-229, Edinburgh. In proceedings.

Golczynski, T.S. and Brown, T.S. (2002) 'Thermal behavior of complex geometric configurations in dry tree risers', Paper OTC-14011 presented at the 2002 Offshore Technology Conference, Houston, Texas. In proceedings.

Golczynski, T.S. and Niessen, V.G. (2001) 'A tale of two trees: flow assurance challenges for wet tree and dry tree systems in ultradeep water', Paper SPE-71545 presented at the 2001 SPE Annual Technical Conference and Exhibition, New Orleans, Louisiana. In proceedings.

Grealish, F. and Roddy, I. (2002) 'State-of-the-art on deep water thermal insulation systems', Paper OMAE2002-28464 presented at the 21st International Conference on OffshoreMechanics and Artic Engineering, Oslo, Norway. In proceedings.

Halvorsen, V.H., Lervik, J.K. and Klevjer, G. (2000) 'Hydrate and wax prevention of risers by electrical methods', In J.S. Chung, R.M.W. Frederking, H. Saeki and W. Koterayama (Eds), Paper presented at the 10th International Offshore and Polar Engineering Conference, Vol. 2, pp.42-48. In proceedings.
Harrison, G.E. and Herring, D.G. (2000) 'Active heating, dual production flowlines design for King sub sea tie-back at 1670 meters water depth', Paper presented at the $O M A E$ 2000/PIPE-5050, ETCE/OMAE2000 Joint Conference, New Orleans. In proceedings.

Jackson, A. and Simonsen, E. (2002) 'Robust design of sub-sea thermal insulation systems for offshore applications', Paper presented at the 3rd Workshop on Sub-sea Pipelines, Rio de Janeiro. In proceedings.

Janoff, D. and Davalath, J. (2002) 'Application of insulation materials for deep water sub-sea completion and production equipment', Paper OTC-14119, presented at the 2002 Offshore Technology Conference, Houston, Texas. In proceedings.

Janoff, D., Davalath, J., Neerland, H., Arevalo, J. and McKie, N. (2002) 'Small and large scale testing of thermal insulation for sub-sea wellhead and production equipment', Paper presented at the 3rd Workshop on Sub-sea Pipelines, Rio de Janeiro. In proceedings.

Kyriakides, S. (2002) 'Buckle propagation in Pipe-In-Pipe systems. Part I: experiments', Int. J. Solids Structures, Vol. 39, pp.351-366.

Kyriakides, S. and Vogler, T.J. (2002) 'Buckle propagation in Pipe-in-Pipe systems. Part II: analysis', Int. J. Solids Structures, Vol. 39, pp.367-392.

Laouir, N. and Denniel, S. (2001) 'Heated PIP: combining passive insulation and active heating for enhanced thermal performance', Paper presented at the 20th International Conference on Offshore Mechanics and Arctic Engineering (OMAE'01), Rio de Janeiro. In proceedings.

Lervik, J.K., Kulbotten, K. and Klevjer, G. (1997) 'Prevention of hydrate formation in pipelines by electrical methods', In J.S. Chung, R.M.W. Frederking, H. Saeki and A.T. Bekker (Eds), Paper presented at the 7th International Offshore and Polar Engineering Conference, Vol. 2, pp.249-254. In proceedings.

Lervik, J.K., Ahlbeck, M., Raphael, H., Lauvdal, T. and Holen, P. (1998) 'Direct electricl heating of pipelines as a method of preventing hydrate and wax plugs', In J.S. Chung, R.M.W. Frederking, H. Saeki and H. Moshagen (Eds), Paper presented at the 8th International Offshore and Polar Engineering Conference, Vol. 2, pp.39-45. In proceedings.

Minami, K., Kurban, A.P.A., Khalil, C.N. and Kuchpil, C. (1999) 'Ensuring flow and production in deep water environments', Paper OTC-11035 presented at the 1999 Offshore Technology Conference, Houston, Texas. In proceedings.

Minami, K., Cardoso, C.A.B.R., Bezerra, M.C.M. and Melo, A.P. (2000) 'Roncador field developement - the impact of fluid properties', Paper OTC-12138 presented at the 2000 Offshore Technology Conference, Houston, Texas. In proceedings.

Murphey, C.E. and Langner, C.G. (1985) 'Ultimate pipe strength under bending, collapse and fatigue', Paper presented at the 4th International Conference on Offshore Mechanics and Arctic Engineering, Vol. 1, pp.467-477. In proceedings.

Nutall, R.H. and Rogers, M.G. (1998) 'Insulated pipe-in-pipe subsea hydrocarbon flowlines', Paper presented at the 17th International Conference on Offshore Mechanics and Arctic Engineering, Lisbon. In proceedings.

Pasqualino, I.P. and Estefen, S.F. (2001) 'Nonlinear analysis of the buckle propagation problem in deep water pipelines', Int. J. Solids Structures, Vol. 38, pp.8481-8502. In proceedings. 
Pausche, M.P., Creek, J.L. and Stair, M.A. (2002) 'Typhoon project: flow assurance issues - how they were identified and resolved', Paper OTC - 14053 presented at the 2002 Offshore Technology Conference, Houston, Texas. In proceedings.

Saint-Pierre, T., Constant, A. and Vu, V.K. (2002) 'Girassol: the management of flow assurance constraints', Paper OTC14169, presented at the 2002 Offshore Technology Conference, Houston, Texas. In proceedings.

Saint-Marcoux, J.F. (2002) 'Hybrid riser towers meet all flow assurance issues of deep and ultra deep field developments', Paper presented at the 3rd Workshop on Sub-sea Pipelines, Rio de Janeiro. In proceedings.

Saint-Marcoux, J.F. and Kennedy, B.F. (2002) Functional Approach to Flow Assurance Applied to Deep Water Field Development, Paragon Engineering.

$\mathrm{Su}, \mathrm{J}$. (2003) 'Flow assurance of deep water oil and gas production - a review', Paper presented at the 22nd International Conference on Offshore Mechanics and Arctic Engineering (OMAE'03), Cancun. In proceedings.

$\mathrm{Su}$, J. and Cerqueira, D.R. (2001) 'Simulation of transient heat-transfer in multi-layered composite pipe', Paper presented at the 20th International Conference on Offshore Mechanics and Arctic Engineering (OMAE'01), Rio de Janeiro. In proceedings.

$\mathrm{Su}$, J., Regis, C.R. and Botto, A. (2002) 'Thermal analysis of combined active heating and passive insulation of deep water pipelines', Paper presented at the 21th International Conference on Offshore Mechanics and Arctic Engineering (OMAE'02), Oslo. In proceedings.
Su, J., Cerqueira, D.R. and Estefen, S.F. (2003) 'Thermal analysis of sandwich pipes with active electrical heating', Paper presented at the 22nd International Conference on Offshore Mechanics and Arctic Engineering (OMAE'03), Cancun. In proceedings.

Su, J., Cerqueira, D.R. and Estefen, S.F. (2005) 'Simulation of transient heat-transfer of sandwich pipes with active electrical heating', ASME Journal Offshore Mechanical Arctic Engineering, Vol. 27, pp.366-370.

Trout, S. and Sahota, B. (1999) 'Shell ETAP high pressure and temperature Pipe-In-Pipe pipeline design and fabrication', Paper presented at the 18th InternationalConference on Offshore Mechanics and Arctic Engineering, Newfoundland. In proceedings.

van Belle, B. (2002) 'Advances in high-temperature syntactic foam technology for offshore systems', Paper OTC-14120 presented at the 2002 Offshore Technology Conference, Houston, Texas. In proceedings.

Warming, R.F. and Beam, R.M. (1975) 'Upwind second-order difference schemes and applications in unsteady aerodynamic flows', Paper presented at the AIAA 2nd Computational Fluid Dynamics Conference, Hartford, Conneticut. In proceedings.

Yeh, M.K. and Kyriakides, S. (1998) 'Collapse of deep water pipelines', ASME Journal Energy Resources Techology, Vol. 110, pp.1-11.

Zhang, J.J., Chen, M.J., Wang, X. and Chacko, J. (2002) 'Thermal analysis and design of hot water heated production flowline bundles', Paper OTC 14015 presented at the 2002 Offshore Technology Conference, Houston, Texas. In proceedings. 